\title{
BMJ Open Effectiveness of diagnostic screening tests in mass screening for COPD using a cooperative regional system in a region with heavy air pollution: a cross-sectional study
}

Kenji Kotaki, Hisao Ikeda, Takeshi Fukuda, Fumiko Yuki, Kanehiro Hasuo, Yuhei Kawano, Masayuki Kawasaki

To cite: Kotaki K, Ikeda H, Fukuda T, et al. Effectiveness of diagnostic screening tests in mass screening for COPD using a cooperative regional system

in a region with heavy air pollution: a cross-sectional study. BMJ Open 2017;7: e012923. doi:10.1136/ bmjopen-2016-012923

- Prepublication history for this paper is available online. To view these files please visit the journal online (http://dx.doi.org/10.1136/ bmjopen-2016-012923).

Received 4 June 2016 Revised 25 October 2016 Accepted 10 November 2016

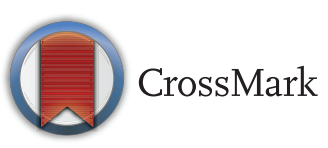

Department of Physical Therapy, Faculty of Fukuoka Medical Technology, Teikyo University, Fukuoka, Japan

Correspondence to

Kenji Kotaki;

koutaki@fmt.teikyo-u.ac.jp

\section{ABSTRACT}

Objectives: This study aimed to evaluate the effectiveness of a cooperative healthcare model for early detection and diagnosis of chronic obstructive pulmonary disease (COPD).

Methods: This was a cross-sectional observational study. We performed diagnosis of COPD at 4 public health centres in Omuta, Japan from March 2015 to March 2016, by adding screening for COPD at the time of routine medical evaluations. All patients aged over 40 years were eligible to participate. Among 397 eligible patients, 293 agreed to participate in the study.

Results: The estimated prevalence of COPD in Ōmuta was $10 \%$ among patients aged over 40 years and was $17 \%$ among smokers. Among those who were screened, over half of them had questionnaire scores over the cut-off of 17 points and decreased FEV1/FVC\%, indicating COPD ( $p>0.05)$. 30 patients with suspected COPD were referred for further investigation at a local central hospital, but only 6 underwent further medical examinations.

Conclusions: The combination of a COPD questionnaire and medical examination is effective as a COPD screening tool. Future research should investigate behavioural interventions for smoking cessation that can be offered in a cooperative model, as well as for improving participation in COPD screening and for encouraging early presentation for treatment in those suspected of having COPD.

\section{INTRODUCTION}

Chronic obstructive pulmonary disease (COPD) occurs as a result of long-term exposure to cigarette smoke and other forms of atmospheric pollution. COPD is characterised by persistent airflow limitation that is usually progressive and associated with a chronic inflammatory response in the airways and lungs. ${ }^{1}$ The incidence of COPD is

\section{Strengths and limitations of this study}

- We were able to determine the percentage of patients with chronic obstructive pulmonary disease who are unknown to the general practitioner and lung physicians.

- We did not collect data on the number of cigarettes smoked, the duration of cigarette smoking or individual exposure to environmental pollutants.

- We did not account for possible confounding factors, such as socioeconomic status and other lifestyle factors.

increasing worldwide, and by 2020, COPD is expected to be the third largest cause of death in the world. ${ }^{2}$ COPD is known as a 'lifestyle disease' of the lungs, and the main cause is smoking. ${ }^{3}$

In recent years, there has been growing concern regarding atmospheric particulate matter (PM) and, in particular, PM smaller than $2.5 \mu \mathrm{m}$ in diameter (PM2.5). PM2.5 particles are small and easily able to penetrate deep into the lung tissue. Therefore, there is concern that rising PM2.5 levels will cause an increase in the incidence of respiratory illness. ${ }^{4}$

Generally, pollution in Japan has decreased following passage of the Pollution-Related Health Damage Compensation Law in 1973, but transboundary air pollution is becoming problematic. Air pollution from China has affected neighbouring Asian countries, and in Japan, its effects are being especially felt on the island of Kyushu. ${ }^{5}$ In response, the Ministry of the Environment has issued interim guidelines in advance of new regulations. These guidelines require that the daily PM2.5 concentration be below $35 \mu \mathrm{g} / \mathrm{m}^{3}$ and 
the yearly average be below $1.8 \mu \mathrm{g} / \mathrm{m}^{3}$, and require maintenance of a continuous monitoring system. ${ }^{6}$ Of further concern, in Kurashiki (in Okayama Prefecture), a previously designated air pollution region, individuals diagnosed with compromised respiratory function did not completely recover even after the air pollution in Kurashiki decreased. ${ }^{7}$

The number of persons seeking treatment for respiratory disease in Japan is reportedly only 260,000 , suggesting that many people are without treatment. Further, the prevalence of COPD in Japan is $\sim 10 \%$, which is lower than the rate of $15-20 \%$ in Western countries. One reason for this difference between countries may be that in Japan the awareness of COPD is low and initial symptoms-breathlessness during exertion, coughing and production of phlegm-are mistaken for the natural phenomena of ageing. ${ }^{89}$

In an attempt to improve the early management of COPD, various providers are attempting early detection. In this pursuit, the International Primary Care Airways Group (IPAG) $\mathrm{COPD}^{10}$ questionnaire, endorsed by the Global Initiative for Chronic Obstructive Lung Disease (GOLD), has been used in combination with spirometry testing, and is reportedly a successful screening strategy. ${ }^{11}$ In the present study, the sensitivity and specificity of the questionnaire in the subgroup of smokers were estimated to be $93 \%$ and $39 \%$, respectively. ${ }^{12}$

As an additional strategy, a cooperative regional system focusing on early diagnosis and treatment has recently been developed. This collaborative effort between universities, medical facilities and health centres has led to improvement in early detection of COPD and prevented exacerbation of this disease and, in turn, reduced health costs. ${ }^{13}$ Health centres and universities jointly performed screening and introduced suspected patients with COPD to medical facilities for early detection and diagnosis of COPD.

On the basis of this success, there might be a need for systematic COPD screening and the creation of cooperative COPD diagnosis models in other regions, especially in regions of air pollution.

This study aimed to replicate this model, with cooperation of the Ömuta Medical Association, health centres and others, and to evaluate the effectiveness of the cooperative COPD diagnosis model in the city of Ōmuta.

\section{METHODS}

\section{Study design and setting}

Screening for COPD was additionally performed during routine health examinations at four different public health centres in Ömuta, in the Fukuoka Prefecture of Japan, from March 2015 to March 2016. All patients who were aged over 40 years were eligible for screening. Among 14383 individuals, 397 persons aged over 40 years underwent a routine examination, and of these, 293 agreed to undergo COPD screening.

\section{Clinical measurements}

The variables examined were age, sex, height, weight, body mass index (BMI), forced vital capacity (FVC), per cent vital capacity $(\% \mathrm{VC})$, forced expiratory volume in $1 \mathrm{~s} \mathrm{(FEV1)} \mathrm{and} \mathrm{FEV1/FVC \% .} \mathrm{Data} \mathrm{were} \mathrm{additionally} \mathrm{col-}$ lected on pre-existing respiratory conditions (bronchial asthma, chronic bronchitis, combined bronchial asthma and chronic bronchitis, or other respiratory illness) and on current smoking status (current smoker, ex-smoker, passive smoker, never smoker).

To determine which patients might have COPD, the IPAG COPD questionnaire (figure 1) and spirometry tests were administered. Spirometry (Autospiro AS-407; Minato) testing was performed according to the Japanese Respiratory Society guidelines. The established criteria for suspicion of COPD were an FEV1/FVC\% score $<70 \%$ before administration of a bronchodilator and a COPD questionnaire score $>17$ points. Patients suspected were referred to local central hospitals for diagnosis. We followed whether a definitive diagnosis was provided and treatment was received at these hospitals.

\section{Air pollution monitoring}

Data on mean monthly concentrations of air pollutants were obtained at central points in Ömuta. Monitoring of PM2.5 and PM10 concentrations started in 2013. We collected data on the concentration of PM2.5 and suspended PM (SPM) in the atmosphere over Ōmuta between December 2013 and March 2015.

\section{Statistical analysis}

The Shapiro-Wilk test was used as a test of normality of the data. The suspected COPD group and non-COPD group were compared with the Mann-Whitney U test. The questionnaire item relating to smoking was examined using the Cochran-Armitage test and the $\chi^{2}$ test. The significance level for all tests was set at 0.05 . PASW for Windows (V.18) was used for the statistical analysis.

All patients provided written consent before data collection began.

\section{RESULTS}

A total of 293 patients agreed to screening for COPD, and of these, 30 were suspected to have COPD. These patients all scored over 17 points on the COPD questionnaire and had an FEV1/FVC\% $<70 \%$ (figure 2); all 30 patients had stage II disease and showed a moderate degree of COPD. The physical characteristics and spirometry results of the screening examination for patients with and without possible COPD are shown in table 1. On the IPAG Questionnaire, responses to the items of production of phlegm, morning production of phlegm, wheezing and presence of allergies were significantly different between patients with and without suspected COPD (table 2). 
Figure 1 IPAG Questionnaire. Sichletidis et al. ${ }^{12}$ BMI, body mass index; IPAG, International Primary Care Airways Guidelines.
Figure 2 Flow chart showing the screening process. FEV\%, FEV1/FVC\% IPAG score, International Primary Care Airways Guidelines Questionnaire score.
COPD Questionnaire

\begin{tabular}{|c|c|c|c|}
\hline \multicolumn{2}{|c|}{ Question } & \multirow{2}{*}{\begin{tabular}{|l} 
Response Choices \\
40-49years \\
\end{tabular}} & \multirow{2}{*}{$\begin{array}{c}\text { Points } \\
0\end{array}$} \\
\hline \multirow{4}{*}{1} & \multirow[t]{4}{*}{ What is your age in years? } & & \\
\hline & & 50-59years & 4 \\
\hline & & 60-69years & 8 \\
\hline & & 70years $\alpha$ older & 10 \\
\hline \multirow{4}{*}{2} & \multirow{4}{*}{$\begin{array}{l}\text { How many cigarettes do you currently smoke each day. } \\
\text { (if you are an ex-smoker,how many did you smoke each day)? } \\
\text { What is the total number of years you have smoked cigarettes? } \\
\text { Pack per day = cigarettes per day } 20 \text { per pack } \\
\text { pack-years = pack per day X years smoked }\end{array}$} & 0-14pack-years & 0 \\
\hline & & 15-24pack-years & 2 \\
\hline & & 25-49pack-years & 3 \\
\hline & & 50+pack-years & 7 \\
\hline \multirow{3}{*}{3} & \multirow{3}{*}{$\begin{array}{l}\text { What is your weight in kilograms? } \\
\text { What is your height in meters? } \\
\text { BMI=w eight in } \mathrm{kg} \text { / (height in } \mathrm{m})^{2}\end{array}$} & $\mathrm{BMI}<25.4$ & 5 \\
\hline & & BMI $<25.4-29.7$ & 1 \\
\hline & & BMI $>29.7$ & 0 \\
\hline \multirow{2}{*}{4} & \multirow[t]{2}{*}{ Is your cough affected by weather? } & Yes & 3 \\
\hline & & No ar no cough & 0 \\
\hline \multirow{2}{*}{5} & \multirow[t]{2}{*}{ Do you suffer from sputum production in the absence of a cold? } & Yes & 3 \\
\hline & & No & 0 \\
\hline \multirow{2}{*}{6} & \multirow[t]{2}{*}{ Do you suffer from sputum production first thing in the morning? } & Yes & 0 \\
\hline & & No & 3 \\
\hline \multirow{2}{*}{7} & \multirow[t]{2}{*}{ How often do you have any wheezing? } & Never & 0 \\
\hline & & Sometimes or often & 4 \\
\hline \multirow{2}{*}{8} & \multirow[t]{2}{*}{ Do you have or did you used to have any allergies? } & Yes & 0 \\
\hline & & No & 3 \\
\hline
\end{tabular}

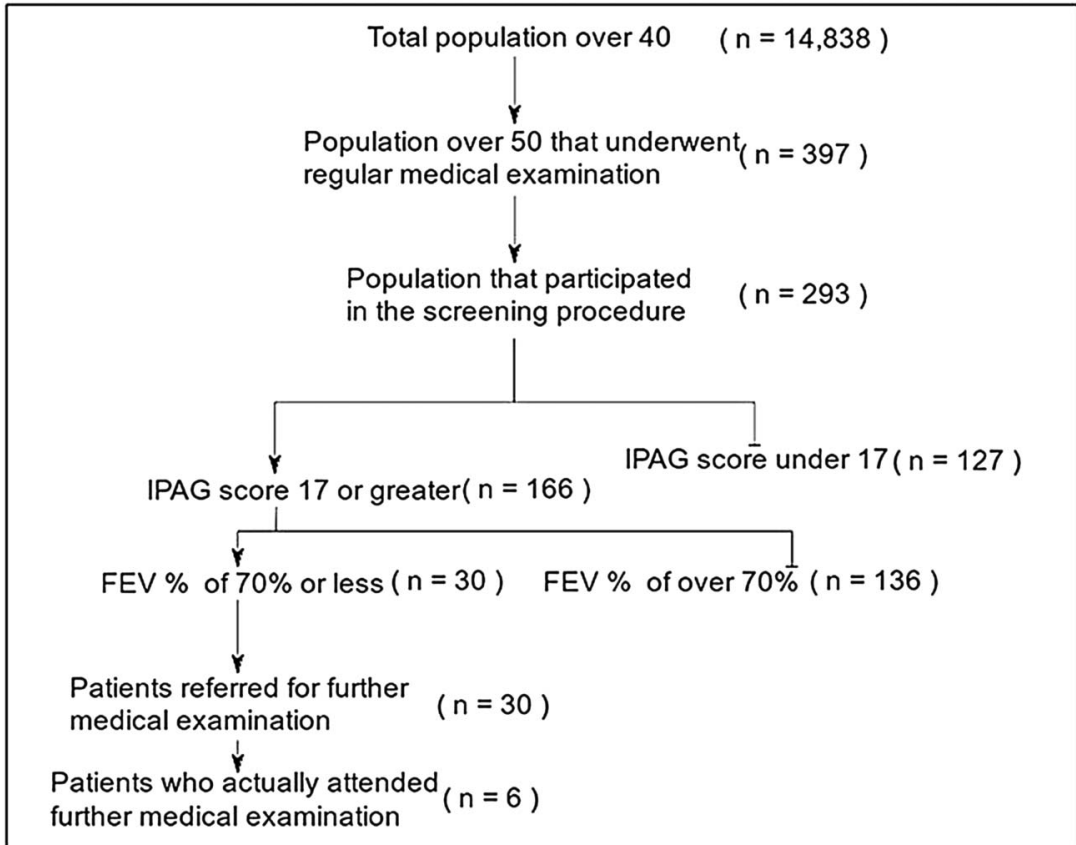

IPAG: International Primary Care Airways Group; FEV\%:
The estimated prevalence of COPD among people aged over 40 years was $10 \%$. Notably, a higher prevalence of COPD was observed in the group of smokers $(21 \%)$ and ex-smokers $(13 \%)$ compared with the passive smokers $(7 \%)$ and non-smokers $(7 \%)$ (table 3 ).

Of the 30 patients with suspected COPD who were referred to local central hospitals, only 6 actually underwent diagnosis. Follow-up of the diagnoses showed one patient with COPD, three patients with bronchial asthma, one patient with lung cancer, and one patient with lung cancer and COPD (table 4).
The mean Ōmuta city PM2.5 concentrations were $23.3 \mu \mathrm{g} / \mathrm{m}^{3}$ in $2012,19.4 \mu \mathrm{g} / \mathrm{m}^{3}$ in 2013 and $20.9 \mu \mathrm{g} / \mathrm{m}^{3}$ in 2014 (all values were greater than the Japanese environmental standard of $15 \mu \mathrm{g} / \mathrm{m}^{3}$ or below). The mean PM10 concentrations were $24.4 \mu \mathrm{g} / \mathrm{m}^{3}, 23.8 \mu \mathrm{g} / \mathrm{m}^{3}$ and $24.1 \mu \mathrm{g} / \mathrm{m}^{3}$, respectively (figure 3 ).

According to the Ministry of the Environment of Japan, the national mean PM2.5 concentrations were $15.4 \mu \mathrm{g} / \mathrm{m}^{3}$ in $2011,14.5 \mu \mathrm{g} / \mathrm{m}^{3}$ in $2012,15.37 \mu \mathrm{g} / \mathrm{m}^{3}$ in 2013 and $15.0 \mu \mathrm{g} / \mathrm{m}^{3}$ in 2014. The mean PM2.5 concentration in Ömuta city was much higher than the recorded national mean value. 
Table 1 Characteristics of the study patients

\begin{tabular}{lllr}
\hline & COPD group $(\mathbf{n}=\mathbf{3 0})$ & Non-COPD group $(\mathbf{n}=\mathbf{2 6 1})$ & $\mathbf{p}$ Value \\
\hline Age & $70.9 \pm 8.1$ & $64.4 \pm 11.9$ & $<0.04$ \\
Sex $(\mathrm{men} /$ women) & $14 / 16$ & $73 / 188$ & $<0.03$ \\
Height $(\mathrm{cm})$ & $158.2 \pm 10.9$ & $157.2 \pm 7.91$ & 0.67 \\
Weight $(\mathrm{kg})$ & $55.3 \pm 10.2$ & $56.9 \pm 10.9$ & 0.46 \\
BMI $\left(\mathrm{kg} / \mathrm{m}^{2}\right)$ & $0.22 \pm 0.03$ & $0.21 \pm 0.02$ & 0.20 \\
FVC $(\mathrm{L})$ & $2.64 \pm 0.95$ & $2.92 \pm 0.74$ & 0.14 \\
$\%$ \%V $(\%)$ & $93.6 \pm 16.7$ & $106 \pm 17.6$ & $<0.00$ \\
FEV1 (L) & $1.6 \pm 0.62$ & $2.22 \pm 0.57$ & $<0.00$ \\
FEV1/FVC\% (\%) & $63.2 \pm 6.1$ & $83.8 \pm 25.2$ & $<0.00$ \\
IPAG score & $22.1 \pm 3.6$ & $16.9 \pm 4.9$ & $<0.00$ \\
Smoking status (smoker+ex-smoker/ & $(14 / 10 / 6)$ & $(75 / 121 / 65)$ & $<0.04$ \\
non-smoker/passive smoker) & & & $<0.00$ \\
\hline BI & $474.65 \pm 560.9$ & $96.81 \pm 267.74$ &
\end{tabular}

Values are presented as mean \pm SD.

Differences in sample characteristics were analysed for significance using the Mann-Whitney $U$ test and Cochran-Armitage test.

$\%$ VC, per cent vital capacity; BMI, body mass index; COPD, chronic obstructive pulmonary disease; FEV1, forced expiratory volume in 1 s; FVC, forced vital capacity; GOLD, Global Initiative for Chronic Obstructive Lung Disease; IPAG, International Primary Care Airways Group.

Table 2 Responses of the COPD questionnaire

\begin{tabular}{|c|c|c|c|c|}
\hline & & COPD group $(n=30)$ & Non-COPD group $(n=261)$ & p Value \\
\hline $\begin{array}{l}\text { CF3:BMl<25.4 kg/m² } \\
\text { Yes (\%) }\end{array}$ & $\mathrm{n}$ & $\begin{array}{l}26 \\
(87 \%)\end{array}$ & $\begin{array}{l}209 \\
(80 \%)\end{array}$ & $<0.04$ \\
\hline $\begin{array}{l}\text { BMI } 25.4-29.7 \mathrm{~kg} / \mathrm{m}^{2} \\
\text { Yes (\%) }\end{array}$ & $\mathrm{N}$ & $\begin{array}{l}4 \\
(13 \%)\end{array}$ & $\begin{array}{l}39 \\
(15 \%)\end{array}$ & $<0.04$ \\
\hline $\begin{array}{l}\text { BMl>29.7 kg/m } \\
\text { Yes (\%) }\end{array}$ & $\mathrm{n}$ & $\begin{array}{l}0 \\
(0 \%)\end{array}$ & $\begin{array}{l}13 \\
(5 \%)\end{array}$ & $<0.03$ \\
\hline $\begin{array}{l}\text { CF4 } \\
\text { Yes (\%) }\end{array}$ & $\mathrm{n}$ & $\begin{array}{l}5 \\
(17 \%)\end{array}$ & $\begin{array}{l}13 \\
(5 \%)\end{array}$ & $<0.03$ \\
\hline $\begin{array}{l}\text { CF5 } \\
\text { Yes (\%) }\end{array}$ & $\mathrm{N}$ & $\begin{array}{l}12 \\
(40 \%)\end{array}$ & $\begin{array}{l}59 \\
(22 \%)\end{array}$ & $<0.01$ \\
\hline $\begin{array}{l}\text { CF6 } \\
\text { Yes (\%) }\end{array}$ & $\mathrm{n}$ & $\begin{array}{l}9 \\
(30 \%)\end{array}$ & $\begin{array}{l}47 \\
(18 \%)\end{array}$ & $<0.02$ \\
\hline $\begin{array}{l}\text { CF7 } \\
\text { Yes (\%) }\end{array}$ & $\mathrm{N}$ & $\begin{array}{l}6 \\
(20 \%)\end{array}$ & $\begin{array}{l}22 \\
(8 \%)\end{array}$ & $<0.03$ \\
\hline $\begin{array}{l}\text { CF8 } \\
\text { Yes (\%) }\end{array}$ & $\mathrm{n}$ & $\begin{array}{l}4 \\
(13 \%)\end{array}$ & $\begin{array}{l}18 \\
(7 \%)\end{array}$ & $<0.04$ \\
\hline
\end{tabular}

BMI, body mass index; COPD, chronic obstructive pulmonary disease.

\section{DISCUSSION}

Owing to the small amount of health promotion performed related to COPD and the difficulty of ensuring medical examinations for all citizens, many individuals are likely to have undiagnosed COPD. In a previous epidemiological study of the prevalence of COPD (the National Institute for Health and Care Excellence (NICE) study), the prevalence was reported to be $8.5 \%$ in the total population, $12.4 \%$ in smokers and $5 \%$ in non-smokers. ${ }^{14}$ The medical examinations performed during this study showed an estimated prevalence of COPD of $10 \%$ in the total group of patients and $21 \%$ in smokers. The reason for a higher estimated prevalence in smokers may be that the double exposure of smoking and pollution has a strong adverse effect on respiratory function and respiratory symptoms. A previous report showed that diagnosed impaired respiratory function related to air pollution in Kurashiki did not recover and, further, that habitual smoking amplified the effects of pollution. ${ }^{15}$ In contrast with the NICE study, in which the authors chose regions to study at random, this study focused on a single limited region. Therefore, differences in exposure to air pollution possibly contributed to the difference in prevalence between studies. ${ }^{14}$ There is also evidence that the rate of awareness of COPD is lower in Japan. As of 2012, COPD was the ninth most common cause of death in Japan, and this disease is predicted to become the third most common disease-related cause of death in the world by 2020 . The number of patients with COPD in Japan receiving treatment is $\sim 260,000$. However, the prevalence of COPD in Japan is much lower than that in Western countries. 
Table 3 Calculation of the prevalence of COPD in Ōmuta

\begin{tabular}{|c|c|c|c|c|c|}
\hline & Total $(\mathrm{N}=293)$ & Smoker $(n=37)$ & Ex-smoker $(n=42)$ & $\begin{array}{l}\text { Passive smoker } \\
(\mathrm{n}=\mathbf{8 1})\end{array}$ & Non-smoker $(n=133)$ \\
\hline $\begin{array}{l}\text { Patients with IPAG score indicating } \\
\text { COPD }\end{array}$ & $166 / 293=0.57$ & $32 / 37=0.86$ & $26 / 42=0.61$ & $38 / 81=0.47$ & $70 / 133=0.53$ \\
\hline $\begin{array}{l}\text { Ratio of those thought to be COPD } \\
\text { after performing spirometry }\end{array}$ & $30 / 166=0.18$ & $8 / 32=0.25$ & $6 / 26=0.23$ & $6 / 38=0.15$ & $10 / 70=0.14$ \\
\hline Patients with both IPAG score and & 14838 & 14838 & 14838 & 14838 & 14838 \\
\hline spirometry indicating COPD & $\times 0.57 \times 0.18=1522.37$ & $\times 0.86 \times 0.25=3190.17$ & $\times 0.61 \times 0.23=2081.77$ & $\times 0.47 \times 0.15=1046.1$ & $\times 0.5 \times 0.14=1100.9$ \\
\hline Prevalence of suspected COPD in & $1522.37 / 14838$ & $3190.17 / 14838$ & $2081.77 / 14838$ & $1046.1 / 14838$ & $1100.9 / 14838$ \\
\hline people aged over 40 years & $\times 100=0.10$ & $\times 100=0.21$ & $\times 100=0.14$ & $\times 100=0.07$ & $\times 100=0.07$ \\
\hline
\end{tabular}

Table 4 Characteristics of the physical state of diagnosed patients

\begin{tabular}{|c|c|c|c|c|c|c|c|c|c|c|c|c|}
\hline Medical examination & Sex & Smokers & IPAG & $\begin{array}{l}\text { Age } \\
\text { (years) }\end{array}$ & $\begin{array}{l}\text { Height } \\
\text { (cm) }\end{array}$ & $\begin{array}{l}\text { Weight } \\
\text { (kg) }\end{array}$ & BMI $\left(\mathrm{kg} / \mathrm{m}^{2}\right)$ & $\begin{array}{l}\text { FVC } \\
\text { (L) }\end{array}$ & $\begin{array}{l}\text { \%VC } \\
(\%)\end{array}$ & $\begin{array}{l}\text { FEV1 } \\
\text { (L) }\end{array}$ & $\begin{array}{l}\text { FEV1/FVC } \\
(\%)\end{array}$ & Diagnosis \\
\hline 1 & Male & Non-smoker & 27 & 76 & 162.3 & 57.2 & 21 & 3.41 & 106.5 & 2.31 & 67.7 & Bronchial asthma \\
\hline 2 & Male & Ex-smoker & 24 & 58 & 152.2 & 55.4 & 23 & 2.36 & 73.5 & 1.67 & 72.3 & Lung cancer \\
\hline 3 & Female & Non-smoker & 17 & 82 & 153.3 & 60.4 & 25 & 1.59 & 76.4 & 0.87 & 54.7 & Bronchial asthma \\
\hline 4 & Female & Smoker & 26 & 71 & 153.4 & 44.4 & 18 & 2.44 & 106.5 & 1.56 & 63.9 & Pulmonary emphysema \\
\hline 5 & Male & Smoker & 30 & 66 & 165.5 & 51.3 & 18 & 3.71 & 103.9 & 2.24 & 60.0 & COPD+lung cancer \\
\hline 6 & Male & Smoker & 22 & 68 & 162.5 & 68.2 & 25 & 3.07 & 90.5 & 1.91 & 62.2 & Bronchial asthma \\
\hline
\end{tabular}




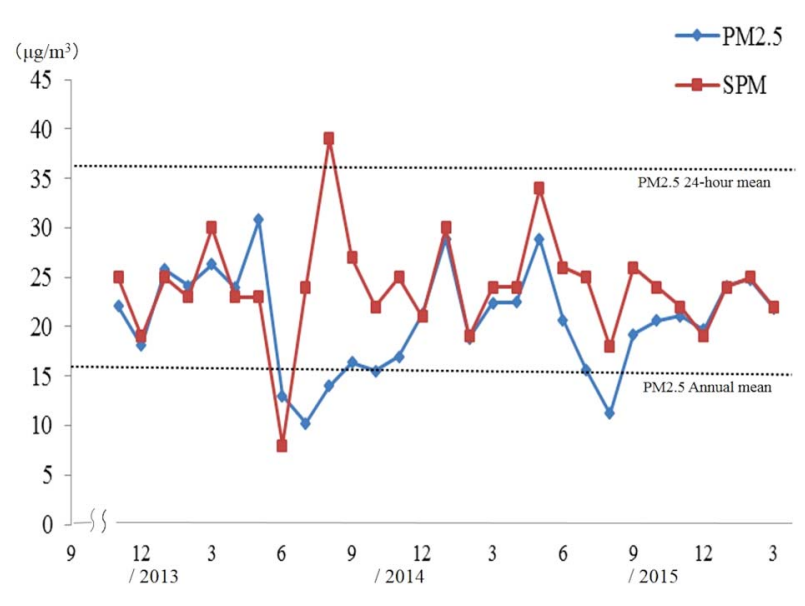

Figure 3 Air pollution monitoring. The annual daily mean levels of PM2.5 and SPM in Ömuta were recorded from 2013 to 2015. PM2.5, particulate matter smaller than $2.5 \mu \mathrm{m}$ in diameter; SPM, suspended particulate matter.

In this study, only $20 \%$ of the patients with suspected COPD who were referred to the central hospital for further diagnosis actually underwent a further medical examination. Since pathological changes are gradual in COPD, patients typically do not seek medical help until their symptoms are severe. ${ }^{16}$ Furthermore, difficulty in accessing healthcare (a distant central hospital in our situation) may have been a factor for older patients.

The findings at the central hospital of three cases of bronchial asthma, two cases of COPD and two cases of lung cancer were surprising in that the number of COPD cases was relatively low. However, chronic bronchitis, bronchial asthma, emphysema and other respiratory conditions were included in the COPD classification. Making a definitive diagnosis may be difficult, and an overlap of symptoms may be observed because of the complex presentation of these diseases.

Asthma or COPD is present in nearly half of the patients with coughing for a period of at least 2 weeks before attending a general practitioner. Most of these can be identified by history taking and a physical examination only. However, in our study, COPD was difficult to diagnose because we were not able to obtain specific or accurate data on the length of the period of coughing. The risk of COPD is increased in patients with a history of asthma. ${ }^{17} 18$ In the two patients who were diagnosed with early-stage lung cancer, the screening strategy detected COPD, and was also effective in detecting other early-stage respiratory illnesses.

The annual mean concentration of PM2.5 in Ömuta is high. The WHO standard value for the daily mean PM2.5 concentration is $25 \mu \mathrm{g} / \mathrm{m}^{3}$ and the annual mean PM2.5 concentration is $10 \mu \mathrm{g} / \mathrm{m}^{3}$. Therefore, the Japan standard is set at a higher level than the international value. In fact, the exposure index normally set for PM10 is used as the PM2.5 index. Notably, the standard relative abundance of PM2.5 to PM10 (PM2.5/PM10) is 0.5, although in developing countries this can vary between
0.5 and 0.8. In recent years in Ōmuta, the mean PM2.5 and PM10 concentrations have sometimes been the same, endangering residents. In the short term, continuous exposure to high concentrations of atmospheric pollution can irritate the throat and cause coughing and inflammation. If the exposure continues for longer than a few months, it can lead to chronic respiratory and circulatory disease. ${ }^{19}$ In this study, we showed that air pollution affects lung function in adults. A previous long-term retrospective study and a long-term prospective cohort study showed that a reduction in air pollution was associated with a decline in FEV1 with a decreased risk of COPD. ${ }^{20}$ Therefore, the number of patients with COPD in Ömuta city is expected to increase, leading to an unpredictable degree of morbidity.

This concern is reflected in the scores on the COPD questionnaire, which were over the cut-off of 17 points for over half of the study patients. The COPD questionnaire was developed in a Western country, and its usefulness in Japan is uncertain. Specifically, the BMI rating is unsuitable for Japanese people, tending to result in higher scores. ${ }^{21}$ However, even in the non-COPD group, more than $50 \%$ of patients reported a cough, phlegm production and wheezing. This finding is unsurprising because a previous study of respiratory symptoms in relation to PM2.5 concentrations showed that at concentrations exceeding $20 \mu \mathrm{g} / \mathrm{m}^{3}$, the OR increases. ${ }^{22}$ An additional finding in our study was that FEV1/FVC\% was low in the spirometry tests. A negative correlation between the concentration of atmospheric pollution and FEV1/FVC\% has previously been reported, as have worsening of symptoms and reduced FVC. ${ }^{23}$

These findings suggest that COPD-related morbidity (and a reduction in quality of life) related to atmospheric pollution is of great concern, especially among smokers. With a $10 \%$ increase in the annual mean PM2.5 concentration, the mortality rate increases by $6 \%{ }^{24}$ Accordingly, continuous efforts are needed to establish cooperative regional COPD intervention systems throughout the region. The GOLD COPD guidelines recommend the introduction of systems that ensure early diagnosis, early access to treatment and support for smoking cessation.

Several drugs are currently available for treatment of COPD symptoms. Patients' shortness of breath, exacerbations, chronic cough and fatigue might be better treated by $\beta-2$ mimetics than by antibiotics. $\beta-2$ mimetics can improve control of symptoms and quality of life, and reduce the number of exacerbations. ${ }^{25} \mathrm{~A}$ reduction in the number of smokers is urgently needed. Support for cessation of smoking has been shown to be the most effective factor in reducing the incidence of COPD and in slowing its progress. This in turn leads to a reduction in associated costs. ${ }^{26}$ Further policy is needed to increase early access to care at central hospitals for persons with possible COPD. In the USA, COPD is associated with much higher medical expenses relative to other respiratory illnesses, ${ }^{27}$ and we predict that COPD will similarly 
become an economic burden on Ōmuta in the future. In our study, a questionnaire was provided that identified four perceived barriers for successful identification of COPD. These barriers were related to the necessity for health providers' assistance and financial compensation, as well as to patients' socioeconomic status and ethnicity. $^{28}$

Other research has reported high reliability and sensitivity when using spirometry tests and questionnaires for the diagnosis of COPD. ${ }^{29}$ This research may have only resulted in few diagnoses, but we believe that a strengthened cooperative regional system can play an important role in preventing respiratory illness.

\section{Limitations of this study}

In this study, we did not have a large number of patients. Therefore, further study with a larger number of patients is required. Another limitation is that we did not investigate specific environmental exposures or the effects of the period of exposure. We were unable to identify which areas that participants lived and worked, how long they had lived in that region, and what their long-term exposure had been. A further limitation is that the number of cigarettes smoked and the duration of smoking were not factored into the analysis. Finally, a smaller number of men than women underwent a routine health examination. Therefore, sex bias may have been present in the data. Further study of the source of exposure, progression of symptoms, including asymptomatic persons, and the use of services related to acute exacerbation will help improve quality of life in the region.

\section{CONCLUSION}

This study examined the effectiveness of a cooperative regional system for COPD screening on previously undiagnosed patients. Our results suggest that a COPD questionnaire and spirometry tests can identify suspected COPD. While all of the patients with suspected COPD were referred for further medical evaluation at specialist facilities, additional future study is required to determine whether diagnosed patients undergo medical treatment at medical centres.

Future research should investigate behavioural interventions for smoking cessation that can be offered in a cooperative model. Additionally, strategies are required for improving participation in COPD screening and for encouraging early presentation for treatment in those suspected as having COPD.

Acknowledgements The authors thank the study participants, technical staff, administrative support team and their coworkers for their assistance. They thank the Omuta Public Health Center and Sugi Hospital for their support. The English language in this manuscript was edited by the Edanz Group (Fukuoka, Japan).

Collaborators Kenji Kotaki, Hisao Ikeda, Takeshi Fukuda, Fumiko Yuki, Kanehiro Hasuo, Yuhei Kawano, Masayuki Kawasaki.
Contributors KK, TF and $\mathrm{HI}$ were the principal investigators and contributed to the design of the study, administered the funding, supervised the work and made critical revisions to the manuscript for intellectual content. KK designed the study, collected, analysed and interpreted the data, and prepared the manuscript. FY and KK participated in data analysis and interpretation, and made critical revisions to the manuscript for intellectual content. KH, YK and TK performed the definitive diagnosis.

Funding This work was supported by the Ōmuta Public Health Center and the National Hospital Organization Ōmuta Hospital.

Competing interests None declared.

\section{Patient consent Obtained.}

Ethics approval The study protocol was approved by the Ethics Committee of Teikyo University Faculty of Fukuoka Medical Technology (approval number: 08072424-2).

Provenance and peer review Not commissioned; externally peer reviewed.

Data sharing statement Additional data can be accessed via the Dryad data repository at http://datadryad.org/ with the doi:10.5061/dryad.7j21m.

Open Access This is an Open Access article distributed in accordance with the Creative Commons Attribution Non Commercial (CC BY-NC 4.0) license, which permits others to distribute, remix, adapt, build upon this work noncommercially, and license their derivative works on different terms, provided the original work is properly cited and the use is non-commercial. See: http:// creativecommons.org/licenses/by-nc/4.0/

\section{REFERENCES}

1. Rabe KF, Hurd S, Anzueto A, et al. Global strategy for the diagnosis, management, and prevention of chronic obstructive pulmonary disease: GOLD executive summary. Am J Respir Crit Care Med 2007;176:532-55.

2. Price DB, Tinkelman DG, Halbert RJ, et al. Symptom-based questionnaire for identifying COPD in smokers. Respiration 2006;73:285-95.

3. Mannino DM, Buist AS. Global burden of COPD: risk factors, prevalence, and future trends. Lancet 2007;370:765-73.

4. Curjuric I, Imboden M, Nadif R, et al. Different genes interact with particulate matter and tobacco smoke exposure in affecting lung function decline in the general population. PLOS ONE 2012;7: e40175.

5. Yang JY, Xin JY, Ji DS, et al. [Variation analysis of background atmospheric pollutants in North China during the summer of 2008 to 2011]. Huan Jing Ke Xue 2012;33:3693-704.

6. WHO. WHO Air quality guidelines for particulate matter, ozone, nitrogen dioxide and sulfur dioxide-Global update 2005-Summary of risk assessment Summary of risk assessment. 2005. http:// whqlibdoc.who.int/hq/2006/WHO_SDE_PHE_OEH_06.02_eng.pdf

7. Tanaka $\mathrm{T}$, Asai $\mathrm{M}$, Yanagita $\mathrm{Y}$, et al. Longitudinal study of respiratory function and symptoms in a non-smoking group of long-term officially-acknowledged victims of pollution-related illness. BMC Public Health 2013;13:766.

8. Kimura K, Kurosaki H, Wakabayashi R, et al. Concerns with the health check-up system for chronic obstructive pulmonary disease on two Japanese islands. Intern Med 2011;50:2135-41.

9. Komase $\mathrm{Y}, \mathrm{Abe} \mathrm{T}$, Kasahara $\mathrm{K}$, et al. Survey on the handling of chronic obstructive pulmonary disease by annual health check in Japan. Intern Med 2008;47:1791-6.

10. Global Initiative for Chronic Obstructive Lung Disease Home page. http:wwwgoldcopdcom (accessed 27 Mar 2007).

11. Qaseem A, Wilt TJ, Weinberger SE, et al. Diagnosis and management of stable chronic obstructive pulmonary disease: a clinical practice guideline update from the American College of Physicians, American College of Chest Physicians, American Thoracic Society, and European Respiratory Society. Ann Intern Med 2011;155:179-91.

12. Sichletidis L, Spyratos D, Papaioannou M, et al. A combination of the IPAG questionnaire and PiKo-6(R) flow meter is a valuable screening tool for COPD in the primary care setting. Prim Care Respir J 2011;20:184-9. 1 p following 89.

13. Tawara $Y$, Senjyu $H$, Tanaka $K$, et al. Value of systematic intervention for chronic obstructive pulmonary disease in a regional Japanese city based on case detection rate and medical cost. Int J Chron Obstruct Pulmon Dis 2015;10:1531-42. 
14. Fukuchi $\mathrm{Y}$, Nishimura $\mathrm{M}$, Ichinose $\mathrm{M}$, et al. COPD in Japan: the Nippon COPD Epidemiology Study. Respirology 2004;9:458-65.

15. Kotaki K, Senjyu H, Tanaka T, et al. Tobacco use among designated air pollution victims and its association with lung function and respiratory symptoms: a retrospective cross-sectional study. BMJ Open 2014;4:e005393.

16. Kornmann O, Beeh KM, Beier J, et al. Newly diagnosed chronic obstructive pulmonary disease. Clinical features and distribution of the novel stages of the Global Initiative for Obstructive Lung Disease. Respiration 2003;70:67-75.

17. Thiadens HA, de Bock GH, Dekker FW, et al. Identifying asthma and chronic obstructive pulmonary disease in patients with persistent cough presenting to general practitioners: descriptive study. BMJ 1998;316:1286-90.

18. Kotz D, Simpson CR, Viechtbauer W, et al. Development and validation of a model to predict the 10-year risk of general practitioner-recorded COPD. NPJ Prim Care Respir Med 2014;24:14011.

19. Ceylan E, Kocyigit A, Gencer M, et al. Increased DNA damage in patients with chronic obstructive pulmonary disease who had once smoked or been exposed to biomass. Respir Med 2006;100:1270-6.

20. Hu G, Zhong N, Ran P. Air pollution and COPD in China. J Thorac Dis 2015;7:59-66.

21. Kawayama T, Minakata $\mathrm{Y}$, Matsunaga $\mathrm{K}$, et al. Validation of symptom-based COPD questionnaires in Japanese subjects. Respirology 2008;13:420-6.
22. Kurmi OP, Semple S, Devereux GS, et al. The effect of exposure to biomass smoke on respiratory symptoms in adult rural and urban Nepalese populations. Environ Health 2014;13:92.

23. Gotschi T, Sunyer J, Chinn S, et al. Air pollution and lung function in the European Community Respiratory Health Survey. Int $J$ Epidemio 2008;37:1349-58.

24. Pope CA III, Burnett RT, Turner MC, et al. Lung cancer and cardiovascular disease mortality associated with ambient air pollution and cigarette smoke: shape of the exposure-response relationships. Environ Health Perspect 2011;119:1616-21.

25. Bhatt SP, Connett JE, Voelker $\mathrm{H}$, et al. $\beta$-Blockers for the prevention of acute exacerbations of chronic obstructive pulmonary disease ( $\beta$ LOCK COPD): a randomised controlled study protocol. BMJ Open 2016;6:e012292.

26. Kaufman G. Chronic obstructive pulmonary disease: diagnosis and management. Nurs Stand 2013;27:53-7. 60-2.

27. Sullivan SD, Ramsey SD, Lee TA. The economic burden of COPD. Chest 2000;117(2 Suppl):5S-9S.

28. Dirven JA, Moser A, Tange HJ, et al. An innovative COPD early detection programme in general practice: evaluating barriers to implementation. NPJ Prim Care Respir Med 2014;24: 14055.

29. Mahboub B, Alzaabi A, Soriano JB, et al. Case-finding of chronic obstructive pulmonary disease with questionnaire, peak flow measurements and spirometry: a cross-sectional study. BMC Res Notes 2014;7:241. 